\title{
Development of Electrospun Wound Dressing for Hemorrage Control using Biominerals
}

\author{
Thamarai Selvan.V, Gobinath.R, Thirumurugan.K, Mekala.N
}

\begin{abstract}
Study says that haemorrhage in trauma accounts for 30-40\% of all fatalities as a cause of death. Wound dressing which can control the blood loss is studied and application of biominerals which is bio compatible got analysed. This field studies on how the mineral particles and textile structures together could be used to design advanced medical products for applications outside human body. From several mineral particles we found one of rock mineral named Montmorillonite is one of mineral particle from soil clay which has high cationic exchange capacity. This controls the haemostasis due to negatively charged particle due to cationic exchange property. These mineral particles are converted into Nano particles and deposited over a nano film and studies are taken. These nano particles delivers high efficient in drug release which leads to faster curing for wound. This nano layer is achieved through textile processed wound dressing electro spinning technology. The proposed system of wound dressing production in electrospinning is by nano film through various combinations and conditions. Due to their nano particle size in electro spun material had advantage on blood clotting is due to superior cationic exchange property while reacting with blood cells results to faster blood clot with reduced pain in healing. Hence the property where studied by comparing nanofilm and coating with powder form and normal dressing. Bio compatibility test is analyzed to compatibility with blood cells of human being through in vitro studies by evaluation by rat cells. Blood clot evaluations are analysed through blood clotting and bleeding time test. In actual bleeding time of normal acute wounds take 240 sec to clot formation hence in our nano film performs clot formation within 40 sec under standard testing conditions.
\end{abstract}

\section{INTRODUCTION:}

Wound dressings are runs in major part of wound care and healing in the medical sector around worldwide. From the ancient times, traditional wound covering with natural or synthetic bandages, cotton wool, lint and gauzes all with varying degrees of absorbency were used for the wound management. Electro spinning is a emerging technique for generation polymeric nano fibres that has a very large surface area to volume ratio. Electro spinning produce nano fibers which have diverse application scaffolds, bio materials and drug delivery systems. However, that is quite difficult to electro spun using chitosan, perhaps reason of intrinsically high viscosity and polyelectrolyte nature. Hence chitosan alone is expensive and the film properties are

Revised Manuscript Received on July 10, 2019

Thamarai Selvan.V, Assistant Professor, Department of Fashion Technology, Bannariamman Institute of Technology, Sathyamangalam.T.N, India.

Gobinath.R, Assistant Professor, Department of Fashion Technology, Bannariamman Institute of Technology, Sathyamangalam. T.N, India.

Thirumurugan.K, Assistant Professor, Department of Fashion Technology, Bannariamman Institute of Technology, Sathyamangalam. T.N, India.

Mekala.N, Assistant Professor, Department of Fashion Technology, Bannariamman Institute of Technology, Sathyamangalam. T.N, India. delicate. To overcome above drawbacks, previous researchers produced films with optimum physical strength from polymer and chitosan solutions using polyvinyl alcohol. PVA-Chitosan blend films with $70 / 30$ ratios were prepared by dissolving the polymers in a solution. Chitosan nanofibres can be prepared by dissolving chitosan in acetic acid. In this study, The chitosan derivatives PVA / chitosan developed and then electrospun using different spinning parameters to produce fibre for their application in wound dressings with analysis of bio compatibility, blood clot and bleeding time tests.

\section{MATERIALS AND METHODOLOGY:}

\subsection{Electro spinning Solution:}

The solvent used to form electrospinning solution was polyvinyl alcohol. The required quantity of PVA and chitosan solution were taken into a bottle and desired amount based on required concentration. Hence $70 \%$ of PVA and $30 \%$ chitosan solution were taken and solution were stirred well. The bottle tightly locked using airtight lid and mounted in the bath. The solution was left overnight and then used for electrospinning. During left the solution it was settle down and form some viscous ability to electro spinning with low wastage in solution.

\subsection{Electro spinning:}

The electro spinning equipment is described with parts like extrusion system (syringe pump), fibre collection system, and high voltage power supply. The system of extrusion or output from the syringe will be controlled by feed rate of the spinning solution existing. The extrusion system was used to provide controlled feed rate of the spinning solution. Electro spinning has its terminals and polymer solution provided with high voltage power from the positive supply. The polymer solution was given a positive field with the help of a high voltage power supply. The positive electrode terminal wire from the high voltage power supply was connected to the extrusion needle $(1 \mathrm{~mm}$ inner diameter). The output of the unit or system of collection of fibres includes a drum. A strip of $12 \mathrm{~cm}$ wide nonwoven made from viscose was mounted carefully around the fibre collecting roller. Gauze with the same dimension was placed over the viscose nonwoven.

\subsection{Preparation of Coating Solution:}

The chitosan was prepared by first dissolving chitosan in acetic acid to yield $1 \%$ aqueous acetic acid solution. Then

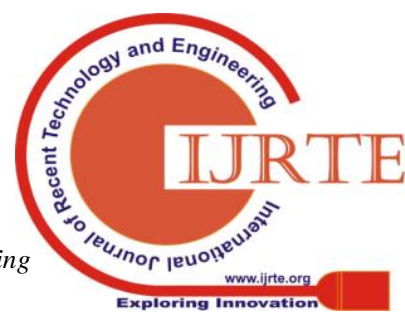




\section{DEVELOPMENT OF ELECTROSPUN WOUND DRESSING FOR HEMORRAGE CONTROL USING BIOMINERALS}

the solution was stirred for 120 mins at 65 Degree Celsius temperature. Then solution of Montmorillonite is prepared by mixing powder form in acetic acid. Dissolving Montmorillonite in $1 \%$ aqueous acetic acid solution then it is stirred for $160 \mathrm{mins}$ at 65 degree Celsius temperature. Both the solution are prepared separately and combining that in proper proportion for coating solution. Combination of chitosan and montmorillonite is taken in three forms they are 50/50, 60/40, 70/30 respectively. These solutions are taken for the coating layer on nano film as we prepared in electrospinning.

\subsection{Spray Coating:}

Prepared solution are taken in beaker and measured. There is three kinds of deposition made on the film they are based on the weight by weight criteria. On weight of nano film $5 \%, 10 \%$, and $15 \%$ are taken as various parameters coated on chitosan/PVA blended nano film in three combinations made during solution preparation. At the first empty base material is weighed and after electrospinning again its weighed. The weight difference is the total volume of nano film. In spray coating machine amount of coating solution were taken on film weight basis. Each $10 \mathrm{ml}$ of combined solution contained $0.1 \mathrm{gm}$ of chitosan and montmorillonite. Hence film weight is ranged in $3 \mathrm{gm}$. The solutions were taken as in content of $5 \mathrm{ml}, 10 \mathrm{ml}$ and $20 \mathrm{ml}$. it is sprayed under normal pressure with $0.1 \mathrm{~mm}$ dia nozzle. Then it is dried under normal room temperature without applying any temperature.

\section{RESULTS AND DISCUSSION}

\subsection{Electrospinning of Blended Solution 70/30} PVA/Chitosan

PVA was used for blending with chitosan solution to provide spinnability of blended solution and to get better mechanical properties of the fibre. Figure shows SEM photographs of nanofibre web that was obtained from the blended solution of chitosan and PVA. At ratio of 70:30 (PVA/chitosan), The viscosity of the blended solution is one of the perceived parameters that affects the structure and diameter of the fibre. The average diameter of the fibre is found to be $112.6 \mathrm{~nm}$.

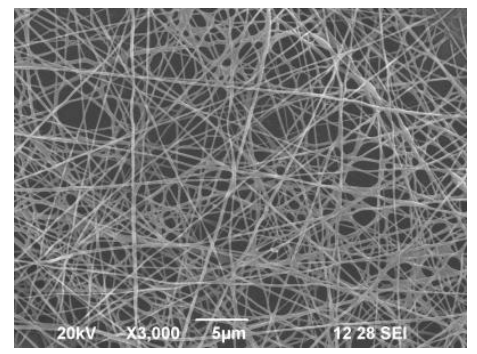

Fig : 1 - SEM (x 3000)

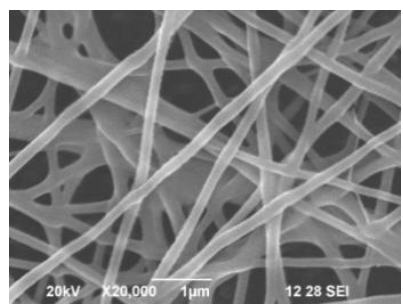

Fig : 2 - SEM (x 20,000)

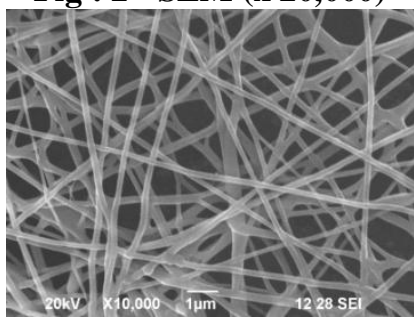

Fig : 3 - SEM (x 10000)

3.2 FTIR Spectral Study:

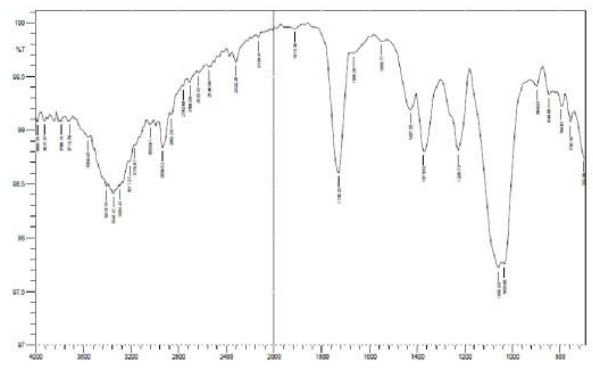

Fig : 4 - FTIR

Anti bacterial activity :

Tab : 1 - Results of Antibacterial Activity

\begin{tabular}{|c|c|c|}
\hline $\begin{array}{c}\text { Sample. } \\
\text { NO }\end{array}$ & $\begin{array}{c}\text { Hours of deposition in } \\
\text { electro spinning (Hrs) }\end{array}$ & $\begin{array}{c}\text { INHIBITION } \\
\text { ZONE IN mm }\end{array}$ \\
\hline 1. & 4.5 & $0.00 \pm 0.00$ \\
\hline 2. & 6.5 & $1.30 \pm 0.45$ \\
\hline 3. & 8.5 & $1.75 \pm 0.30$ \\
\hline
\end{tabular}

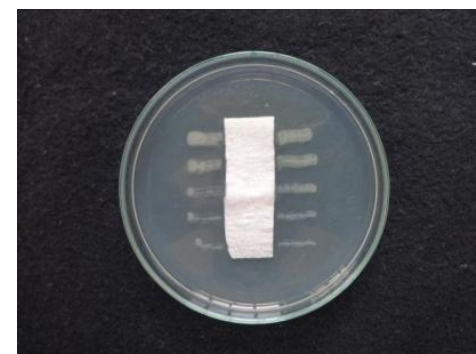

Fig : 5 - Sample 2

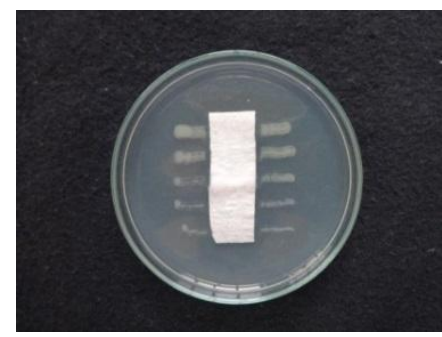

Fig : 6 - Sample 3

3.3 Bleeding Time Analysis :

Tab : 2 - Results of Bleeding Time

\begin{tabular}{|l|l|l|}
\hline S. NO & Samples & BLEEDING TIME [SECS] \\
\hline 1. & $15 \%$ coated & 32 \\
\hline 2. & $10 \%$ coated & 71 \\
\hline 3. & $5 \%$ coated & 105 \\
\hline
\end{tabular}




\subsection{Blood Clotting Time :}

Tab : 3 - Results of Blood Clotting Time

\begin{tabular}{|l|l|l|}
\hline S. NO & Samples & CLOTTING TIME [MINS] \\
\hline 1. & $15 \%$ coated & $2 \mathrm{~min} 33 \mathrm{sec}$ \\
\hline 2. & $10 \%$ coated & $6 \mathrm{~min} 52 \mathrm{sec}$ \\
\hline 3. & $5 \%$ coated & $8 \mathrm{~min} 45 \mathrm{sec}$ \\
\hline
\end{tabular}

3.5 Drug Release Test :

Tab : 4 - Optical density measured for the release concentrations of Chitosan from the fabric samples

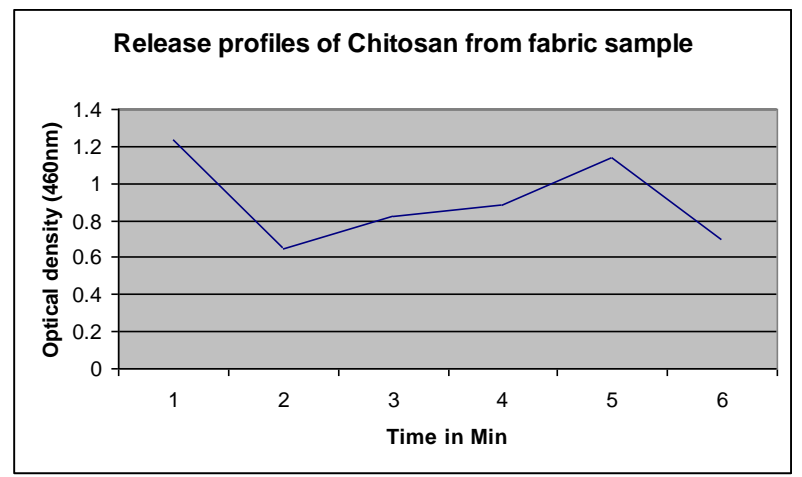

Fig : 7 - Release profiles of electro-spun chitosan from fabric samples

\subsection{Bio Compatibility Test:}

No irritation scores (IS) was developed for the sample during the contact period of sample on CAM according to the standard IS [B] analysis. When compared to negative control no irritation endpoints were developed on CAM for the treated sample. So the provided sample was considered to be biocompatible.

\section{CONCLUSION}

From this research, PVA/Chitosan nanocomposite layer were prepared by emerging method called electro spinning. The ration based on weight of PVA: Chitosan was applied at $70: 30$ in $1 \%$ Acetic acid. The suitable concentration condition of the solution for Chitosan / Montmorillonite deposition is derived in the ratio of 70/30 through drug release evaluation due to the maximum fiber yield. Further more good deposition of coating on nano film was resulted as $15 \%$ through bleeding time and blood clotting evaluation hence final product is evaluated in wound healing in a rat model results in Montmorillonite is having good in blood clotting function and combined with that chitosan having higher efficacy in faster rate of wound healing. The result says about Montmorillonite is good in blood clotting but making some restrictions to releasing drug. Hence lower concentration of Montmorillonite gives blood clotting with good rate of wound healing in higher combination of chitosan.

\section{REFERENCE :}

1. K Tarun \& N Gobi "Calcium alginate/PVA blended nano fibre matrix for wound dressing" Indian Journal of Fibre \& Textile Research Vol. 37, June 2012, pp. 127-132.
2. Joseph Deitzel et al.., "Generation of Polymer Nanofibers Through Electrospinning" Journal of Biomaterials and Nanobiotechnology, 2, 55-64 june 1999.

3. Monica Sanandam et al..,"Chitosan Bandage For Faster Blood Clotting And Wound Healing" Biochemical Engineering \& Biotechnology. International Journal of Advanced Biotechnology and Research ISSN 0976-2612, Vol 4, Issue 1, 2013, pp 47-50

4. K. Paipitak et al.., "Characterization of PVA-Chitosan Nanofibers Prepared by Electrospinning" 2nd International Science and Social-Science, Engineering and Energy Conference 2010: Engineering Science and Management.

5. Gerlach T, "Preliminary study of the effects of smectite granules (WoundStat) on vascular repair and wound healing in a swine survival model" journal of surgery, Division of Trauma and Emergency Surgery, Department of Surgery, UC Davis Medical Center, Sacramento, USA. travis.gerlach@ucdmc.ucdavis.edu

6. http://en.wikipedia.org/wiki/Wound, From Wikipedia, the free encyclopedia

7. http://www.ncbi.nlm.nih.gov/pmc/articles/PMC1420733/

8. Francoise Arnaud, $\mathrm{PhD}$ et al.., "Comparison of $\mathbf{1 0}$ Hemostatic Dressings in a Groin Transection Model in Swine" Journal of Trauma. 2009;67: 848-855.

9. Patrícia B. Malafaya et al.., "Natural-origin polymers as carriers and scaffolds for biomolecules and cell delivery in tissue engineering applications"

10. R. Jayakumar et al.., "Novel Chitin and Chitosan Materials in Wound Dressing" Biomedical Engineering, Trends in Materials Science

11. Biomedical Engineering, Trends in Materials Science, Biomedical Engineering, Trends in Materials Science

12. http://www.mindat.org/min-2821.html

13. K.P. Chellamani, "Medical Textiles: The Spunlace process and its application possibilities for hygiene textiles" Journal of Acad. Indus. Res. Vol. 1(12) May 2013

14. http://www.spunlace-nonwovens.com/Spunlacenonwoven $17 . \mathrm{html}$

15. Xinying Geng et al.., "Electrospinning of chitosan dissolved in concentrated acetic acid solution" journal of Biomaterials 26 (2005) 5427-5432 